\title{
Article \\ Community-Based Rehabilitation Indicators: Validation and Preliminary Evidence for Disability in Italy
}

\author{
Marco Tofani ${ }^{1,2, *(\mathbb{D})}$, Giuseppina Esposito ${ }^{3} \mathbb{D}$, Anna Berardi ${ }^{4}$, Giovanni Galeoto ${ }^{4}\left(\mathbb{D}\right.$, Silvia Iorio ${ }^{5}$ \\ and Maurizio Marceca ${ }^{1}$ (D)
}

1 Department of Public Health and Infectious Diseases, Sapienza University of Rome, 00185 Rome, Italy; maurizio.marceca@uniroma1.it

2 Department of Intensive Neurorehabiiltation and Robotics, Bambino Gesù Pediatric Hospital IRCCS, 00165 Rome, Italy

3 Traumatic and Orthopedic Center A. Alesini, 00145 Rome, Italy; pinaespo@gmail.com

4 Department of Human Neurosciences, Sapienza University of Rome, 00185 Rome, Italy; anna.berardi@uniroma1.it (A.B.); giovanni.galeoto@uniroma1.it (G.G.)

5 Department of Medico-Surgical Sciences and Biotechnologies, Sapienza University of Rome, 00185 Rome, Italy; silvia.iorio@uniroma1.it

* Correspondence: marco.tofani@uniroma1.it

Citation: Tofani, M.; Esposito, G.; Berardi, A.; Galeoto, G.; Iorio, S.; Marceca, M. Community-Based Rehabilitation Indicators: Validation and Preliminary Evidence for Disability in Italy. Int. J. Environ. Res. Public Health 2021, 18, 11256. https:// doi.org/10.3390/ijerph182111256

Academic Editor: Koutatsu Nagai

Received: 10 September 2021

Accepted: 25 October 2021

Published: 26 October 2021

Publisher's Note: MDPI stays neutral with regard to jurisdictional claims in published maps and institutional affiliations.

Copyright: (c) 2021 by the authors. Licensee MDPI, Basel, Switzerland. This article is an open access article distributed under the terms and conditions of the Creative Commons Attribution (CC BY) license (https:// creativecommons.org/licenses/by/ $4.0 /)$.

\begin{abstract}
Community-based rehabilitation (CBR) is a multi-sectorial community strategy for guaranteeing that people with disabilities enjoy the same rights and opportunities as all other community members. CBR is organized in a five-component matrix — namely, health, education, social, livelihood, and empowerment. To measure the effectiveness of CBR, the World Health Organization (WHO) has developed standardized indicators. The objective of the present study is to translate and validate the CBR indicators (CBR-Is), providing preliminary evidence of their use for disability in Italy. After obtaining permission from the WHO, the CBR-Is followed a process of translation and cross-cultural adaptation according to international guidelines. An examination of internal consistency and reliability was than performed. The intra-rater reliability was estimated using the Intraclass Correlation Coefficient with a 95\% confidence interval. In order to measures the differences between people with and without disabilities, an independent sample $t$-test was used for quantitative indicators. The Italian version of the CBR-Is (IT-CBR-Is) was administered to 234 people. The internal consistency showed a good value, with a Cronbach's alpha coefficient of 0.862 , and the intra-rater reliability analysis showed solid values for each domain (range: 0.723-0.882). Statistically significant differences between people with and without disabilities were found for each domain of the CBR matrix - namely, health, social, education, livelihood, and empowerment. The IT-CBR-Is are consistent and reliable measures when used to investigate disability in a community-based inclusive development perspective. National stakeholders can now have specific indicators to implement services and actions for people with disabilities.
\end{abstract}

Keywords: disability; community-based rehabilitation; community-based inclusive development; reliability; indicators

\section{Introduction}

Community-based rehabilitation (CBR), also known as community-based inclusive development, is a community action to ensure that people with disabilities have the same rights and opportunities as all other community members [1]. It was initiated by the World Health Organization (WHO) following the International Conference on Primary Health Care where the Alma-Ata Declaration was approved in 1978 [2]. In 2003, an international meeting was held to define recommendations for CBR [3]. Subsequently, the International Labor Organization (ILO), the United Nations Educational, Scientific, and Cultural Organization (UNESCO), and the WHO signed a joint "position paper" to propose 
CBR as a strategy for rehabilitation, equalization of opportunities, poverty reduction, and social inclusion of people with disabilities [4]. In 2005, the WHO Assembly adopted a resolution for disability prevention and rehabilitation by urging Member States to promote and strengthen CBR programs [5]. CBR was finally included in the Global Disability Action Plan 2014-2021 [6]. The action plan was endorsed by WHO Member States in 2014 and calls for them to: (a) remove barriers and improve access to health services and programs; (b) strengthen and extend rehabilitation, assistive devices and support services, and community-based rehabilitation; (c) enhance collection of relevant and internationally comparable data on disability and conduct research on disability and related services. Achieving the objectives of the action plan better enables people with disabilities to fulfill their aspirations in all aspects of life [6].

To date, CBR strategies have been developed in more than 90 countries. When measuring effectiveness, qualitative approaches have taken the upper hand in CBR and remain highly relevant. However, there is also a call for the inclusion of quantitative indicators in order to capture the progress made by people participating in CBR programs [7]. Moreover, CBR has a positive and significant impact on access to services, rights, and opportunities of people with disabilities [8], and has demonstrated its efficacy in low- and middle-income countries [9]. However, the methodological constraints of many of these studies limit the strength of their results. In order to build stronger evidence, future studies will need to adopt better study designs while also focusing on broader client groups and including economic evaluations [10]. There is also a need for changes in CBR evaluation methodologies in response to the evolution of disability models from medical models to human rights models while also considering the diversity among persons with disabilities in interpreting life experiences and their quality of life [11]. Therefore, in order to support the growth of CBR worldwide, there is also a need for a strong evidence on the effectiveness of the programs $[12,13]$.

The lack of data for supporting the effectiveness of $C B R$ is due, in part, to the absence of standardized indicators [14]. For this reason, the WHO and IDDC CBR Task Force decided to work together to develop indicators and questions to inform them. Indicators were developed in four steps: (1) analysis of all work pertaining to CBR; (2) reprogramming of desirable CBR results contained in the CBR Guidelines; (3) creation of an Alpha Version of CBR indicators; (4) feasibility and validity testing [15]. The CBR Indicators Manual proposes a simple and flexible data collection strategy that can be customized based on the desired indicators [16]. The indicators correspond to the components of the CBR matrix (health, education, livelihood, social life, and empowerment) and each of their five subelements, and they have been outlined on the basis of the desirable outcomes of CBR set out in the CBR Guidelines [15].

The CBR indicators (CBR-Is) can be used to register the differences between people who live with/without a condition of disability in each domain of the CBR matrix. The CBR-Is can be used by managers, community workers, volunteers, researchers, and other stakeholders interested in the implementation of CBR. Moreover, these indicators can be used to assess the current situation and monitor the differences that CBR is making in the lives of people with disabilities in the areas where it is implemented. It is also possible to use the indicators to monitor other action plans/interventions within communities. Considering that in Italy, there are several projects with a community-based approach [17-19] and a need for monitoring programs from a community-based perspective, the objective of this investigation is to: (a) translate and culturally adapt the CBR-Is into Italian; (b) evaluate its reliability, particularly its internal consistency and inter-rater reliability; (c) measure the differences between people with and without disabilities in each domain of the CBR matrix.

\section{Materials and Methods}

This investigation was carried out by researchers from Sapienza University of Rome and the Rehabilitation and Outcome Measures Assessment (ROMA) Association. The re- 
search group was involved in the validation of different outcome measures, with particular interest in disabilities and global health education [20-22].

\subsection{Assessment Tool}

The CBR-Is [15] are composed of 40 core and supplementary indicators. The 13 core CBR-Is are divided as follows: two for health, six for education, three for livelihood, one for social, and one for the empowerment component. The core CBR-Is are able to register differences between people with and without disabilities, regardless of individual CBR programs, as well as specific activities. The use of the core CBR-Is is recommended as a minimum set to assess the effectiveness and monitor the progress of CBR programs. Instead, the remaining $27 \mathrm{CBR}$-Is can be selected based on specific community needs according to each component of the CBR matrix. For more information, please see the CBR Indicators Manual available on the WHO website [16].

\subsection{Translation and Cross-Cultural Adaptation}

After receiving permission from the WHO, the CBR-Is were translated and culturally adapted according to international guidelines. The original version was translated into Italian by two native English speakers, who produced two independent translations. An independent native Italian speaker then synthesized the results of the two translations into one document. Two Italian translators then translated that document back into the English language without having seen the original English version of the CBR-Is. The back-translated version of the instrument was then compared with the original English version. In order to adapt the translated version to Italian culture, five Italian health professionals (two medical doctors and three rehabilitation professionals) - familiar with both the English and Italian languages and with a great deal of experience with CBR-reviewed the first translated version and then reworded and reformulated some items to minimize the differences from the original version. After obtaining the pre-final version, in order to be sure about the comprehensibility of the scale, a pre-test was conducted, involving five people with and without disabilities. The equivalence of the two versions was investigated in regard to their semantic domains. The Italian version of the CBR-Is (IT-CBR-Is) was formed as a result of the translation and cross-cultural adaptation process.

\subsection{Sampling, Procedure, and Data Analysis}

Individuals were recruited from community settings from various parts of Italy between March 2018 and March 2019. The convenience sample met the following inclusion criteria: healthy people and/or people who had a condition of disability, aged 18 years or older. A convenience sample was recruited from different community settings, again from different areas of the country. Recruitment strategies included the use of email invitations to different people, acquaintances, senior centers, university students, and employees. As recommended by the Consensus-Based Standards for the Selection of Health Status Measurement Instruments (COSMIN) [23,24], a sample size of at least 100 persons was deemed adequate for internal consistency and reliability, and at least 200 people were adequate for investigating cross-cultural validity. Consequently, the research group decided to recruit a minimum sample size of 200 people.

Before starting, the research group participated in an internal training course in order to level out confidence with the outcomes and indicators. Lessons focusing on theoretical and practical activities regarding the administration of the IT-CBR-Is were also organized. Socio-demographic information was obtained from direct interviews with the participants. According to the COSMIN, in order to evaluate internal consistency, Cronbach's alpha coefficient was used. Internal consistency measures the relatedness of the items and consistency of the scale [25] - it was calculated for the total score of the IT-CBR-Is. As reported by Nunually [26], a satisfactory index of the homogeneity of the scale should have at least an alpha of 0.70 . For the reliability study, the intra-rater reliability was investigated with the intraclass correlation coefficient (ICC) with $95 \%$ confidence intervals. 
Intra-rater reliability was determined by the evaluation of the same individual at different moments within a week. The ICC estimates ranged from 0 (no agreement) to 1 (perfect agreement) and were interpreted as follows: $0.00-0.25$, little or no correlation; $0.26-0.50$, low correlation; $0.51-0.070$, moderate correlation; $0.71-0.90$, high correlation; $0.91-1$, very high correlation $[25,27]$.

In order to obtain preliminary evidence on how the IT-CBR-Is can capture the differences between people with and without disabilities, an independent sample $t$-test was applied for questions in which it was possible to transform nominal variables into numerical variables, as provided in the original manual produced by the WHO. Therefore, some questions of a descriptive nature were excluded (e.g., H06 and H09: "Which reason(s) explain(s) why you did not get that health/rehabilitation service?") or other questions related to the use of assistive technologies. Significance was set to $p<0.05$ with $95 \%$ confidence intervals. All analyses were performed by using the Statistical Package for the Social Sciences (SPSS) version 24.0 (IBM Corp. Released 2016. IBM SPSS Statistics for Windows, Version 24.0. IBM Corp., Armonk, NY, USA).

\section{Results}

The IT-CBR-Is were administered to 234 individuals: 40 people with disabilities (mean age: 42, SD: 14.26) and 194 without disabilities (mean age: 38, SD: 13.12). The sample was homogeneous for age and gender. The majority of the population were residents in central and southern Italy. The characteristics of the sample are summarized in Table 1.

Table 1. Sample characteristics (sample: $n=234$ ).

\begin{tabular}{cccc}
\hline & $\begin{array}{c}\text { People with } \\
\text { Disabilities }\end{array}$ & $\begin{array}{c}\text { People without } \\
\text { Disabilities }\end{array}$ & t-Student \\
\hline Age mean (SD) & $42(14.26)$ & $38(13.12)$ & 0.070 \\
Gender & 16 & 64 & \\
Female & 24 & 130 & \\
Male & 40 & 194 & \\
Total & 0 & & \\
\hline Regional Location & 33 & 12 & \\
Northern Italy & 7 & 68 & \\
Central Italy & & & \\
Southern Italy & &
\end{tabular}

Regarding the reliability study, the internal consistency measured with Cronbach's alpha coefficient was 0.862 for the whole scale. The ICCs with $95 \%$ confidence intervals for intra-rater reliability were within the range of $0.723-0.882$. The ICC values for each subscale of the IT-CBR-Is are reported in Table 2.

Table 2. Reproducibility of the community-based rehabilitation indicators (sample: $n=234$ ).

\begin{tabular}{cccc}
\hline Component & ICC & Lower Bound & Upper Bound \\
\hline Health & 0.744 & 0.694 & 0.789 \\
Education & 0.723 & 0.697 & 0.749 \\
Livelihood & 0.739 & 0.647 & 0.754 \\
Social & 0.882 & 0.859 & 0.903 \\
Empowerment & 0.796 & 0.756 & 0.833 \\
\hline
\end{tabular}

ICC: Intraclass correlation coefficient.

Regarding differences between people with and without disabilities, statistically significant differences were found in each domain of the CBR matrix: namely, three for health, four for social, three for education, two for livelihood, and three for empowerment. Table 3 describes the differences among people with and without disabilities for each domain of the IT-CBR-Is in greater depth. 
Table 3. $t$-Student analysis for independent samples (total: 234).

\begin{tabular}{|c|c|c|c|c|c|}
\hline Questions & $\begin{array}{l}\text { Without Disabilities } n=194 \\
\text { Mean (SD) }\end{array}$ & $\begin{array}{l}\text { With Disabilities } n=40 \\
\text { Mean (SD) }\end{array}$ & Mean Difference & $t$ & $p$ \\
\hline H01. In general, how would you rate your health today? & $1.72(0.64)$ & $3.25(0.54)$ & -1.528 & -14.094 & 0.000 * \\
\hline $\begin{array}{l}\text { H02. On your last visit to a health-care provider, to what extent were you } \\
\text { satisfied with the level of respect you were treated with? }\end{array}$ & $3.22(1.13)$ & $2.90(0.95)$ & 0.316 & 1.646 & 0.101 \\
\hline $\begin{array}{l}\text { E01. What is the highest level of education you have achieved, or are } \\
\text { working to achieve? }\end{array}$ & $5.54(1.28)$ & $4.70(1.47)$ & 0.836 & 3.646 & 0.000 * \\
\hline L02. Do you have enough money to meet your needs? & $2.79(0.85)$ & $2.65(0.58)$ & 0.144 & 1.020 & 0.309 \\
\hline $\begin{array}{l}\text { S01. Do you feel that other people respect you? For example, do you feel } \\
\text { that others value you as a person and listen to what you have to say? }\end{array}$ & $3.26(0.89)$ & $2.80(1.04)$ & 0.458 & 2.871 & 0.004 * \\
\hline $\begin{array}{l}\text { M01. Do you get to make the big decisions in your life? For example, } \\
\text { deciding who to live with, where to live, or how to spend your money? }\end{array}$ & $3.98(1.04)$ & $2.95(1.03)$ & 1.029 & 5.667 & $0.000 *$ \\
\hline $\begin{array}{l}\text { H03. Has your (doctor, CBR worker, or any other health professional) ever } \\
\text { discussed with you the benefits of eating a healthy diet, engaging in regular } \\
\text { physical exercise, or not smoking? }\end{array}$ & $1.15(0.36)$ & $1.05(0.22)$ & 0.105 & 1.758 & 0.080 \\
\hline H04. When was the last time you had a regular health check-up? & $1.38(0.71)$ & $1.30(0.96)$ & 0.081 & 0.617 & 0.538 \\
\hline $\begin{array}{l}\text { H07. On your last visit to a health-care provider, to what extent were you } \\
\text { involved in making decisions for your treatment? }\end{array}$ & $2.94(1.37)$ & $2.90(1.00)$ & 0.038 & 0.167 & 0.868 \\
\hline $\begin{array}{l}\text { H08. In the last } 12 \text { months, has there been a time when you needed } \\
\text { rehabilitation services, such as physical, occupational, or speech therapy, } \\
\text { but did not get those services? }\end{array}$ & $2.70(0.69)$ & $2.20(0.75)$ & 0.501 & 4.097 & $0.000 *$ \\
\hline $\begin{array}{l}\text { E04. Do you participate in learning opportunities to improve your skills for } \\
\text { everyday life or work? }\end{array}$ & $1.30(0.61)$ & $1.55(0.54)$ & -251 & -2.423 & $0.016^{*}$ \\
\hline E05. To what extent does it fit your needs? & $2.42(1.44)$ & $1.60(1.51)$ & 0.823 & 3.250 & 0.001 * \\
\hline L03. Do you get to decide how to use your money? & $4.23(1.00)$ & $3.05(1.17)$ & 1.177 & 6.556 & 0.000 * \\
\hline $\begin{array}{l}\text { L04. Do you know how to get financial services such as credit, insurance, } \\
\text { grants, savings programs? }\end{array}$ & $1.11(0.62)$ & $1.05(0.81)$ & 0.063 & 0.552 & 0.581 \\
\hline
\end{tabular}


Table 3. Cont.

\begin{tabular}{|c|c|c|c|c|c|}
\hline Questions & $\begin{array}{l}\text { Without Disabilities } n=194 \\
\text { Mean (SD) }\end{array}$ & $\begin{array}{l}\text { With Disabilities } n=40 \\
\text { Mean (SD) }\end{array}$ & Mean Difference & $t$ & $p$ \\
\hline $\begin{array}{l}\text { L05. Do you currently benefit from any social protection program, such as } \\
\text { loss of income through old age, sickness, or disability? }\end{array}$ & $1.48(0.88)$ & $1.20(0.75)$ & 0.285 & 1.887 & 0.060 \\
\hline $\begin{array}{l}\text { L06. Do you know how to get social protection against loss of income } \\
\text { resulting from old age, sickness, or disability? }\end{array}$ & $1.97(0.45)$ & $1.55(0.54)$ & 0.419 & 5.112 & 0.000 * \\
\hline $\begin{array}{l}\text { S02. Do you get to make decisions about the personal assistance that you } \\
\text { need (who assists you, what type of assistance, when to get assistance)? }\end{array}$ & $3.47(1.59)$ & $3.20(1.26)$ & 0.274 & 1.025 & 0.306 \\
\hline S04. Do you get to participate in artistic, cultural, or religious activities? & $3.43(1.41)$ & $2.15(1.36)$ & 1.283 & 5.266 & 0.000 * \\
\hline $\begin{array}{l}\text { S05. Do you get to participate in community recreational, leisure, and } \\
\text { sports activities? }\end{array}$ & $3.37(1.38)$ & $2.15(1.54)$ & 1.221 & 4.981 & 0.000 * \\
\hline S06. To what extent do you know your legal rights? & $2.95(0.94)$ & $2.65(0.80)$ & 0.298 & 1.858 & 0.064 \\
\hline S07. Do you know how to access the justice system? & $1.12(0.80)$ & $1.20(0.68)$ & -0.076 & -0.559 & 0.577 \\
\hline $\begin{array}{l}\text { M02. Do you think that the policies in your country provide people with } \\
\text { disabilities equal rights to those of other people? }\end{array}$ & $2.01(0.89)$ & $1.95(1.08)$ & 0.060 & 0.374 & 0.709 \\
\hline $\begin{array}{l}\text { M03. Are you satisfied with your ability to persuade people of your views } \\
\text { and interests? }\end{array}$ & $2.90(0.96)$ & $2.05(1.03)$ & 0.847 & 5.010 & 0.000 * \\
\hline M04. Do you get to influence the way your community is run? & $2.01(1.10)$ & $1.55(0.74)$ & 0.460 & 2.524 & $0.012 *$ \\
\hline M05. Did you vote in the last election? & $1.05(0.26)$ & $1.05(0.38)$ & 0.002 & 0.031 & 0.975 \\
\hline $\begin{array}{l}\text { M07. To what extent do you feel Disabled People's Organizations } \\
\text { adequately represent your concerns and priorities? }\end{array}$ & $2.24(1.30)$ & $2.30(1.10)$ & -0.063 & -0.288 & 0.774 \\
\hline
\end{tabular}




\section{Discussion}

This study reports the Italian translation and cross-cultural adaptation of the CBR-Is and provides preliminary evidence on the IT-CBR-Is' reliability and validity for use with people with and without disabilities aged 18 years or older.

The translation followed current international guidelines. During the pre-test phase, the involvement of both experts and recipients proved extremely useful. As a matter of fact, this step led to an improvement in the comprehensibility of the questions and their adaptation to the specific Italian context. For example, for question H10, "Do you use any aids to help you get around, such as a cane, crutch, or wheelchair; or to help you with self-care, such as grasping bars or a hand or arm brace?", the expert suggested translating "hand or arm brace" as "ortesi" (orthotics) due to the fact that this wording is more technically appropriate. However, when we applied the pre-test phase with the target population, they reported that they did not understand what "ortesi" meant. After explaining the meaning and following a careful debate, the research group opted to translate with "tutori per la mano o l'arto superiore" (hand or upper limb brace) because this wording is more appropriate for non-technical staff. Furthermore, the CBR-Is can also be used with community-based rehabilitation workers or other personnel who lack specific training with medical aspects. Consequently, creating a version that was easy to understand appears to be important. Another relevant aspect to be considered is the specific adaptation for the Italian context. For example, we considered the different educational systems among countries. In the original version, for question E01 ("What is the highest level of education you have achieved, or are working to achieve?), different answers were provided. However, these responses were not appropriate for the Italian school system due to the fact that in Italy, there is no college. In order to solve this challenge, experts were consulted-while also gaining an understanding of the target population's point of view - and the research group contacted the WHO headquarters; by working together, they found a solid solution. The final manual of the IT-CBR-Is was finally approved by the authors and the WHO [28].

The IT-CBR-Is revealed good internal consistency (Cronbach's alpha coefficient of 0.862), meaning that that all items were related to each other and that they positively contributed to measuring the same general construct. For the intra-rater reliability, the IT-CBR-Is showed good stability over time (within a week), especially for the social component (0.882) and empowerment (0.796) components. These encouraging results provide preliminary evidence for using the IT-CBR-Is and monitoring action plans at different levels. However, the lack of other validation studies does not allow for a comparison with other countries.

Interesting topics of the present investigation were the differences between people with and without disabilities for each domain of the CBR. First and foremost, the health component revealed that people with disabilities experienced poor health outcomes $(p<0.0001)$ and barriers to gaining access to health care $(p<0.0001)$ and rehabilitation services $(p<0.0001)$ compared to people without disabilities. This finding is in line with the World Report on Disability [13] and the recent report on access to health-care services for people with disabilities [29]. Secondly, the education component highlighted the difficulties of people with disabilities in obtaining higher education in comparison with people without disabilities $(p<0.0001)$, as well as in attending formal and informal training for skill development $(p=0.016)$ (please note that according to the manual, in this case, the most penalizing value was the highest one). Moreover, this finding is in line with those of the World Report on Disability [13] and several studies [30,31]. For livelihood, people with disabilities were more dependent on the use of their own money $(p<0.0001)$, and they did not know how to obtain social assistance, such as for loss of income through old age, sickness, or disability $(p<0.0001)$. Furthermore, regarding the social component, significant differences were found. People with disabilities felt that they were treated with little respect and that they were not considered equal to others $(p=0.004)$; they could not make decisions about their personal relationships $(p<0.0001)$ or participate in cultural 
activities $(p<0.0001)$ or leisure activities $(p<0.0001)$. The findings show that a focus on social inclusion in the labor market is lacking, and the main barriers identified were related to financial factors, attitudes, health issues, and unemployment [32]. However, studies suggest that higher physical and leisure/recreation activities are associated with better quality of life [33]. Lastly, the empowerment component revealed that people with disabilities lack the necessary independence in order to make the big decisions in their lives $(p<0.0001)$, influence the community where they live $(p=0.012)$, and persuade people of their views and interests $(p<0.0001)$.

The results of this study initially confirm preliminary evidence of the indicators in recording the differences between people with and without disabilities in different areas of their lives. Despite the fact that Italy ratified the United Nations' Convention on the Rights of Persons with Disabilities, there are still many challenges to be faced in order to achieve equity in health and access to services and to promote active participation in their social and political lives while also guaranteeing the possibility of enjoying the same rights as other people.

Despite these encouraging results, the present study has some limitations. Firstly, the relatively small sample size does not allow for a generalization of the results. Moreover, using a convenience sample may have affected the ability to reach some people who were likely to have greater needs. There are no other validation studies of the CBR-Is, and consequently, this does not allow for a comparison of our findings with similar studies. Lastly, the study did not include children with and without disability. Further studies should consider these aspects.

\section{Conclusions}

In conclusion, this investigation shows the consistency and reliability of the IT-CBR-Is as tools for measuring differences between people with and without disabilities. Consequently, Italian healthcare professionals and policymakers, as well as government at the local and national levels, can now measure the impact of their actions along with the effectiveness of their interventions from a community-based inclusive development perspective.

Author Contributions: Conceptualization, methodology, formal analysis, M.T. and M.M.; investigation and writing, A.B. and G.G.; writing - review and editing, G.E. and S.I. All authors have read and agreed to the published version of the manuscript.

Funding: The APC was funded by Sapienza University of Rome, PhD School in Infectious Diseases, Microbiology, and Public Health.

Institutional Review Board Statement: The study was conducted according to the guidelines of the Declaration of Helsinki. Ethical review and approval were waived for this study due to the explorative nature of the study and the non-intervention.

Informed Consent Statement: Informed consent was obtained from all subjects involved in the study.

Data Availability Statement: The data presented in this study are available on reasonable request from the corresponding author.

Acknowledgments: The authors are grateful to Elena Stacy Mazzone (Università Cattolica del Sacro Cuore), Franco Macera (AIFO—Associazione Italiana Amici di Raoul Follereau), Ivano Mattozzi (Local Health Autority of Viterbo and ARIBaC ONLUS), Emanuele Montobbio (MSF, Medicins Sans Froniters), and Alda Pellegri (OVCI—Organizzazione di Volontariato per la Cooperazione Internazionale) for their kind contributions and professionalism. The authors would also like to thank all participants who agreed to participate in the present study.

Conflicts of Interest: The authors declare no conflict of interest. 


\section{References}

1. World Health Organization. Meeting Report on the Development of Guidelines for Community Based Rehabilitation (CBR) Programmes. 2004. Available online: https://www.who.int/disabilities/publications/cbr/050405_CBR_guidelines_1st_meeting_ report.pdf (accessed on 12 October 2021).

2. World Health Organization. Declaration of Alma-Ata. 1978. Available online: https://www.who.int/publications/almaata_ declaration_en.pdf (accessed on 26 May 2021).

3. World Health Organization. International Consultation to Review Community-Based Rehabilitation (CBR). 2003. Available online: http:/ / www.who.int/ncd/disability (accessed on 26 May 2021).

4. World Health Organization. CBR: A Strategy for Rehabilitation, Equalization of Opportunities, Poverty Reduction and Social Inclusion of People with Disabilities: Joint Position Paper 2004; 27p. Available online: https://apps.who.int/iris/handle/10665/ 43060 (accessed on 26 May 2021).

5. World Health Organization. Disability, Including Prevention, Management and Rehabilitation. 2005. Available online: https: / / www.who.int/disabilities/WHA5823_resolution_en.pdf?ua=1 (accessed on 26 May 2021).

6. World Health Organization. WHO Global Disability Action Plan 2014-2021. 2015. Available online: https://apps.who.int/iris/ bitstream/handle/10665/199544/9789241509619_eng.pdf?sequence=1\&isAllowed=y (accessed on 26 May 2021).

7. Grandisson, M.; Hébert, M.; Thibeault, R. A systematic review on how to conduct evaluations in community-based rehabilitation. Disabil. Rehabil. 2013, 36, 265-275. [CrossRef] [PubMed]

8. Mauro, V.; Biggeri, M.; Deepak, S.; Trani, J.F. The effectiveness of community-based rehabilitation programmes: An impact evaluation of a quasi-randomised trial. J. Epidemiol. Community Health 2014, 68, 1102-1108. [CrossRef] [PubMed]

9. Bokalial, D.; Hossain, M.F.; Kumar, N.S.; Bajracharya, S. Effectiveness of Community-Based Rehabilitation on the lives of Parents of Children with Cerebral Palsy: A Mixed Method Study in Karnataka, India. Disabil. CBR Incl. Dev. 2020, 31, 23-45. [CrossRef]

10. Iemmi, V.; Gibson, L.; Blanchet, K.; Kumar, K.S.; Rath, S.; Hartley, S.; Murthy, G.V.; Patel, V.; Weber, J.; Kuper, H. Community-based rehabilitation for people with disabilities in low-and middle-income countries: A systematic review. Campbell Syst. Rev. 2015, 11, 1-177. [CrossRef]

11. Shumba, T.W.; Haufiku, D.; Mitonga, K.H. The evolution of community-based rehabilitation (CBR) programmes: A call for mixed evaluation methodologies. J. Health Res. 2020, 34, 505-514. [CrossRef]

12. Finkenflügel, H.; Wolffers, I.; Huijsman, R. The evidence base for community-based rehabilitation: A literature review. Int. J. Rehabil. Res. 2005, 28, 187-201. [CrossRef]

13. World Health Organization. World Report on Disability. 2011. Available online: www.who.int/about/licensing/copyright_form/ en/index.html (accessed on 26 May 2021).

14. Evans, P.; Zinkin, P.; Harpham, T.; Chaudury, G. Evaluation of community-based rehabilitation for disabled persons in developing countries. Soc. Sci. Med. 2001, 53, 333-348. [CrossRef]

15. Mason, C.; Weber, J.; Atasoy, S.; Sabariego, C.; Cieza, A. Development of indicators for monitoring Community-Based Rehabilitation. PLoS ONE 2017, 12, e0178418. [CrossRef]

16. World Health Organization. Community-Based Rehabilitation Indicators Manual Capturing the Difference We Make. 2015. Available online: www.who.int (accessed on 26 May 2021).

17. Iorio, S.; Salvatori, L.M.; Barnocchi, A.; Battisti, A.; Rinaldi, A.; Marceca, M.; Paglione, L. Social inequalities in the metropolitan area of Rome. A multidisciplinary analysis of the urban segregation of the "formerly-Bastogi" compound. Ann Ig 2019, 31, 211-229. [CrossRef] [PubMed]

18. Paglione, L.; Bargagli, A.M.; Agabiti, N.; Calandrini, E.; Salvatori, L.M.; Marceca, M.; Baglio, G.; Brandimarte, M.A.; Iorio, S.; Davoli, M.; et al. Urban health and inequalities in highly socially marginalised settings in Rome. Epidemiol. Prev. 2020, 44, 38-44. [CrossRef]

19. Benvenuto, A.; Battan, B.; Benassi, F.; Gialloreti, L.E.; Curatolo, P. Effectiveness of community-based treatment on clinical outcome in children with autism spectrum disorders: An Italian prospective study. Dev. Neurorehabilit. 2014, 19, 1-9. [CrossRef] [PubMed]

20. Civitelli, G.; Tarsitani, G.; Rinaldi, A.; Marceca, M. Medical education: An Italian contribution to the discussion on global health education. Glob. Health 2020, 16, 30. [CrossRef]

21. Nobilia, M.; Culicchia, G.; Tofani, M.; De Santis, R.; Savona, A.; Guarino, D.; Valente, D.; Galeoto, G. Italian Version of the Jebsen-Taylor Hand Function Test for the Assessment of Hand Disorders: A Cross-Sectional Study. Am. J. Occup. Ther. 2019, 73, 7303205080p1-7303205080p6. [CrossRef]

22. Civitelli, G.; Tarsitani, G.; Rinaldi, A.; Marceca, M. Long-term impact of Global Health educational experiences in Rome: An attempt of measurement. Arch. Public Health 2020, 78, 90. [CrossRef]

23. Mokkink, L.B.; Terwee, C.B.; Patrick, D.L.; Alonso, J.; Stratford, P.; Knol, D.L.; Bouter, L.; de Vet, H.C. The COSMIN study reached international consensus on taxonomy, terminology, and definitions of measurement properties for health-related patient-reported outcomes. J. Clin. Epidemiol. 2010, 63, 737-745. [CrossRef]

24. Terwee, C.B.; Prinsen, C.A.C.; Chiarotto, A.; Westerman, M.J.; Patrick, D.L.; Alonso, J.; Bouter, L.; De Vet, H.C.W.; Mokkink, L.B. COSMIN methodology for evaluating the content validity of patient-reported outcome measures: A Delphi study. Qual. Life Res. 2018, 27, 1159-1170. [CrossRef]

25. Monticone, M.; Galeoto, G.; Berardi, A.; Tofani, M. Psychometric Properties of Assessment Tools. In Measuring Spinal Cord Injury; Springer International Publishing: Berlin/Heidelberg, Germany, 2021; pp. 7-15. [CrossRef] 
26. Makhoul, J. Linear prediction: A tutorial review. Proc. IEEE 1975, 63, 561-580. [CrossRef]

27. Ratner, B. The correlation coefficient: Its values range between $+1 /-1$, or do they? J. Target. Meas. Anal. Mark. 2009, 17, 139-142. [CrossRef]

28. Tofani, M.; Galeoto, G.; Esposito, G. Capturing the Difference We Make Manuale per Gli Indicatori della Riabilitazione Su Base Comunitaria; Edizioni ROMA: Rome, Italy, 2019.

29. Kuper, H.; Phyllis, H. The Missing Billion Access to Health Services for 1 Billion People with Disabilities; London School of Hygiene and Tropical Medicine: London, UK, 2019. [CrossRef]

30. Iezzoni, L.I. Public Health Goals for Persons with Disabilities: Looking Ahead to 2020. Disabil. Health J. 2009, 2, 111-115. [CrossRef] [PubMed]

31. Lamichhane, K. Disability and barriers to education: Evidence from Nepal. Scand. J. Disabil. Res. 2013, 15, 311-324. [CrossRef]

32. Hästbacka, E.; Nygård, M.; Nyqvist, F. Obstacles et facilitateurs à la participation dans la société des personnes qui présentent une incapacité: Vue d'ensemble des études portant sur la situation en Europe. Alter 2016, 10, 201-220. [CrossRef]

33. Vanner, E.A.; Block, P.; Christodoulou, C.C.; Horowitz, B.P.; Krupp, L.B. Pilot study exploring quality of life and barriers to leisure-time physical activity in persons with moderate to severe multiple sclerosis. Disabil. Health J. 2008, 1, 58-65. [CrossRef] [PubMed] 